\title{
Erratum to: ACL prosthesis: any promise for the future?
}

\author{
Jon Karlsson
}

Published online: 4 November 2010

(C) Springer-Verlag 2010

The corresponding author Dr. Bernardino Saccomanni submitted this article [2] to Knee Surgery Sports Traumatology Arthroscopy (KSSTA). The article was published in the journal in 2010. It has been brought to our attention that this article has major similarities to an article published in the McGill journal in 2008 [1]. A duplicate publication with an obvious case of plagiarism has thus taken place. The editors of KSSTA, who act according to the COPE Code of Conduct, consider this an infringement of professional ethics, and therefore the decision has been taken to retract this article published in KSSTA. An apology is extended to our readers, the authors of the article in the McGill journal, as well as the readers, and editorial and publishing staff of the journal.

\section{References}

1. Mascarenhas R, Macdonald PB (2008) Anterior cruciate ligament reconstruction: a look at prosthetics-past, present and possible future. McGill J Med 11:29-37

2. Saccomanni B (2010) ACL prosthesis: any promise for the future? Knee Surg Sports Traumatol Arthrosc 18:797-804

The online version of the original article can be found under doi:10.1007/s00167-009-0982-y.

J. Karlsson ( $\square)$

Department of Orthopaedics,

Sahlgrenska University Hospital, 43180 Mölndal, Sweden

e-mail: jon.kssta@gmail.com 